2006-03-01

\title{
Integrated Antenna for Multiband Multi-national Wireless Combined with GSM1800/PCS1900/IMT2000 + Extension
}

Matthias John

Technological University Dublin, matthias.john@tudublin.ie

Max Ammann

Technological University Dublin, max.ammann@tudublin.ie

Follow this and additional works at: https://arrow.tudublin.ie/ahfrcart

Part of the Systems and Communications Commons

\section{Recommended Citation}

John, M. \& M. J. Ammann,(2006) Integrated Antenna for Multiband Multi-National Wireless Combined with GSM/800/PCS1900/IMT2000+Extensio, Microwave and Optical Technology Letters, vol. 48, no. 3, pp. 613-615, 03/2006. doi:10.1002/mop.21423

This Article is brought to you for free and open access by the Antenna \& High Frequency Research Centre at ARROW@TU Dublin. It has been accepted for inclusion in Articles by an authorized administrator of ARROW@TU

Dublin. For more information, please contact

arrow.admin@tudublin.ie, aisling.coyne@tudublin.ie, gerard.connolly@tudublin.ie.

Funder: Science Foundation Ireland

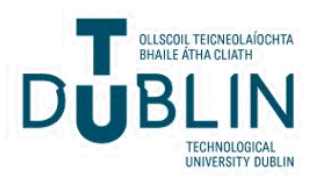




\title{
Integrated Antenna for Multiband Multi-National Wireless combined with GSM1800 / PCS1900 / IMT2000 + Extension
}

\author{
M. John and M. J. Ammann \\ Centre for Telecommunications Value-chain driven Research \\ School of Electronic \& Communications Engineering \\ Dublin Institute of Technology, Kevin Street, Dublin 8 \\ IRELAND \\ Email: matthias.john@student.dit.ie
}

\begin{abstract}
A printed triple-band monopole antenna appropriate for use as a terminal antenna in modern wireless multiband systems is proposed. The impedance bandwidth of each band has been optimised using a quasi-Newton technique and the bandwidth includes virtually all wireless bands. Various parameter sweeps are presented which improve the understanding of the antenna, in particular, the effect of groundplane-size and branch-off point on impedance bandwidth and radiation pattern.
\end{abstract}

\section{Introduction}

The proliferation of wireless communications devices has placed many new demands on antenna designers. The requirements of terminal antennas to be small, low-cost, have quasi-isotropic patterns over wide or multiple bandwidths and be integratable into radio circuitry are generally not always simultaneously achievable. Many tradeoffs are commonly made, juggling between parameters. Printed monopoles have been recently proposed as suitable contenders with many variations suggested for dualband operation, including a multibranch technique $[1,2]$ and also the use of $F$ and $\mathrm{S}$ shapes $[3,4]$. The multibranch technique has already been employed with monopoles, using classical groundplanes [5]. In this paper, a novel simple multibranch monopole printed on low-cost laminate is proposed as a triple-band terminal antenna, contributing many of the requirements for a wireless terminal antenna. These antennas are proposed for the emerging multi-band wireless transceivers, which operate over a wide range of bands as dictated by national authorities. 


\section{Antenna Geometry}

The monopole is printed on one side of a low-cost FR4 substrate with a square groundplane located on the back. The substrate properties are $(t=1.52 \mathrm{~mm}, 35 \mu \mathrm{m}$, $\operatorname{Dk}(2 \mathrm{GHz})=4.3, \tan \delta(2 \mathrm{GHz})=0.02)$. The substrate dimensions are $l=45 \mathrm{~mm}$ by $w=80 \mathrm{~mm}$ by $t=1.52 \mathrm{~mm}$. For a square groundplane, $l_{g}=45 \mathrm{~mm}$. The microstrip feedline width is $w_{f}=2 \mathrm{~mm}$. The dimensions of the multibranch radiator are $l_{m}=28 \mathrm{~mm}$, $l_{l}=15.8 \mathrm{~mm}, w_{l}=4 \mathrm{~mm}, l_{r}=10.6 \mathrm{~mm}$ and $w_{r}=4 \mathrm{~mm}$. The branch-off point is located $h_{t}=2 \mathrm{~mm}$ above the groundplane. These dimensions were obtained using a quasiNewton opimiser, optimising for the widest bandwidth of the three wireless bands. The antenna geometry is shown in Figure 1.

\section{Simulation and Measurement}

Modelling was performed using CST Microwave Studio, using the finite-integration time-domain technique and a waveguide port for the feed. Measured return loss for the optimised element is shown in Figure 2, which is in good agreement with measured data. The measurements were made using a Rohde \& Schwarz ZVB network analyser. The three bands in which the measured return loss in greater than $10 \mathrm{~dB}$ are $1.78 \mathrm{GHz}$ to $2.68 \mathrm{GHz}, 3.4 \mathrm{GHz}$ to $3.68 \mathrm{GHz}$ and $4.85 \mathrm{GHz}$ to greater than $6 \mathrm{GHz}$. The lower band includes GSM1800/PCS1900, IMT-2000, the $2.45 \mathrm{GHz}$ ISM band, WLAN, IEEE $802.11 \mathrm{~b}, \mathrm{~g}$ and the IMT-2000 Extension band $(2.5-2.7 \mathrm{GHz})$. The middle band includes WiMax and WLL. The upper band covers IEEE 802.11j, a, the US-NII and the $5.8 \mathrm{GHz}$ ISM band. Due to the dispersion in substrate loss, the simulated radiation efficiency drops from $89 \%$ at $2 \mathrm{GHz}$ to $69 \%$ at $6 \mathrm{GHz}$.

\section{Parameter Dependence}

The dependence of impedance bandwidth on the height of the tap-off point $\left(h_{t}\right)$ was investigated for the three bands. The height $h_{t}$ was varied from $0 \mathrm{~mm}$ to $4 \mathrm{~mm}$ and the return loss was examined. The bandwidth of all three bands is shown in Figure 3. The upper and middle bands show maximum bandwidth for tap-off heights between $1.5 \mathrm{~mm}$ and $2.5 \mathrm{~mm}$. The lower band bandwidth increases steadily with tap-off height. The groundplane size was also varied from $20 \times 20 \mathrm{~mm}$ to $100 \times 100 \mathrm{~mm}$ square. The bandwidth of all three bands is shown in Figure 4. The upper band shows maximum bandwidth for groundplane sizes above $40 \mathrm{~mm}$. The lower band has its optimum 
bandwidth from $40 \mathrm{~mm}$ to $50 \mathrm{~mm}$ groundplane size. The middle band shows little dependence on groundplane size. It should be noted that the FR4 loss can contribute significantly to antenna bandwidth at the upper band, but its contribution at the lower and middle band is negligible. This is seen in Figure 4, where a plot for a lossless dielectric is shown. The lower edge frequency (LEF) of the low band also is somewhat dependent on groundplane size. It has been shown [6] that the LEF is lowest for GP sizes of 40 to $45 \mathrm{~mm}$.

\section{Radiation Patterns}

Measured radiation patterns are presented in Figure 5. The maximum gain was found to be $3.0 \mathrm{dBi}$ at $2 \mathrm{GHz}, 2.5 \mathrm{dBi}$ at $3.4 \mathrm{GHz}$ and $3.4 \mathrm{dBi}$ at $5.5 \mathrm{GHz}$. The patterns exhibit quasi-omnidirectional patterns in the $x-y$ plane as shown in Figure 5a. The $x-z$ and $y-z$ cuts are in Figure $5 \mathrm{~b}$ and $5 \mathrm{c}$.

\section{Conclusion}

A printed tripleband multibranch monopole was presented. The dependence of impedance bandwidth on groundplane size and branch-off point was shown for each band. A wireless-optimised triple-band printed monopole was presented.

\section{Acknowledgements}

This work has been supported by the Science Foundation Ireland. 


\section{References}

1 M. J. Ammann, and R Farrell,

"Dual-Band Monopole Antenna with Stagger-Tuned Arms for Broadbanding,"

IEEE International Workshop on Antenna Technology: Small Antennas and Metamaterials. 2005, 278281

2. M. John and M. J. Ammann,

"The Effect Of Groundplane Size And Branch Off Point On The Performance Of The Printed Multibranch Monopole,"

Loughborough Antennas \& Propagat. Conf. 2005, 189-192.

3. S. H Yeh and K. L Wong,

"Integrated F Shaped Monopole Antenna for 2.4/5.2 Dual-Band Operation,"

Microwave \& Optical Technology Letters, 2002, (34), 24-26.

4. W. C. Liu, W. R.Chen and C. M. Wu,

"Printed Double S-shaped Monopole Antenna for Wideband and Multiband Operation of Wireless Communications," IEE Proc. MAP. 2004, 151, (6), 473-476.

5. D. Liu,

"Branch Number and Height Effects on the Multi-Branch Dual-Band Monopole Antenna," IEEE APS Simp Dig 2000, 1302-1305

6. M. John, M. J. Ammann and R. Farrell, "Printed Triband Terminal Antenna,"

IEE Conf., Wideband and Multiband Antennas and Arrays, 2005, (to be published) 


\section{Figure captions}

Figure 1: Geometry and coordinate system of the printed multibranch monopole

Figure 2: Measured and simulated return loss for optimised geometry

Figure 3: Impedance bandwidth dependence on tap-off point

Figure 4: Impedance bandwidth dependence on groundplane size

Figure 5: Measured radiation patterns 

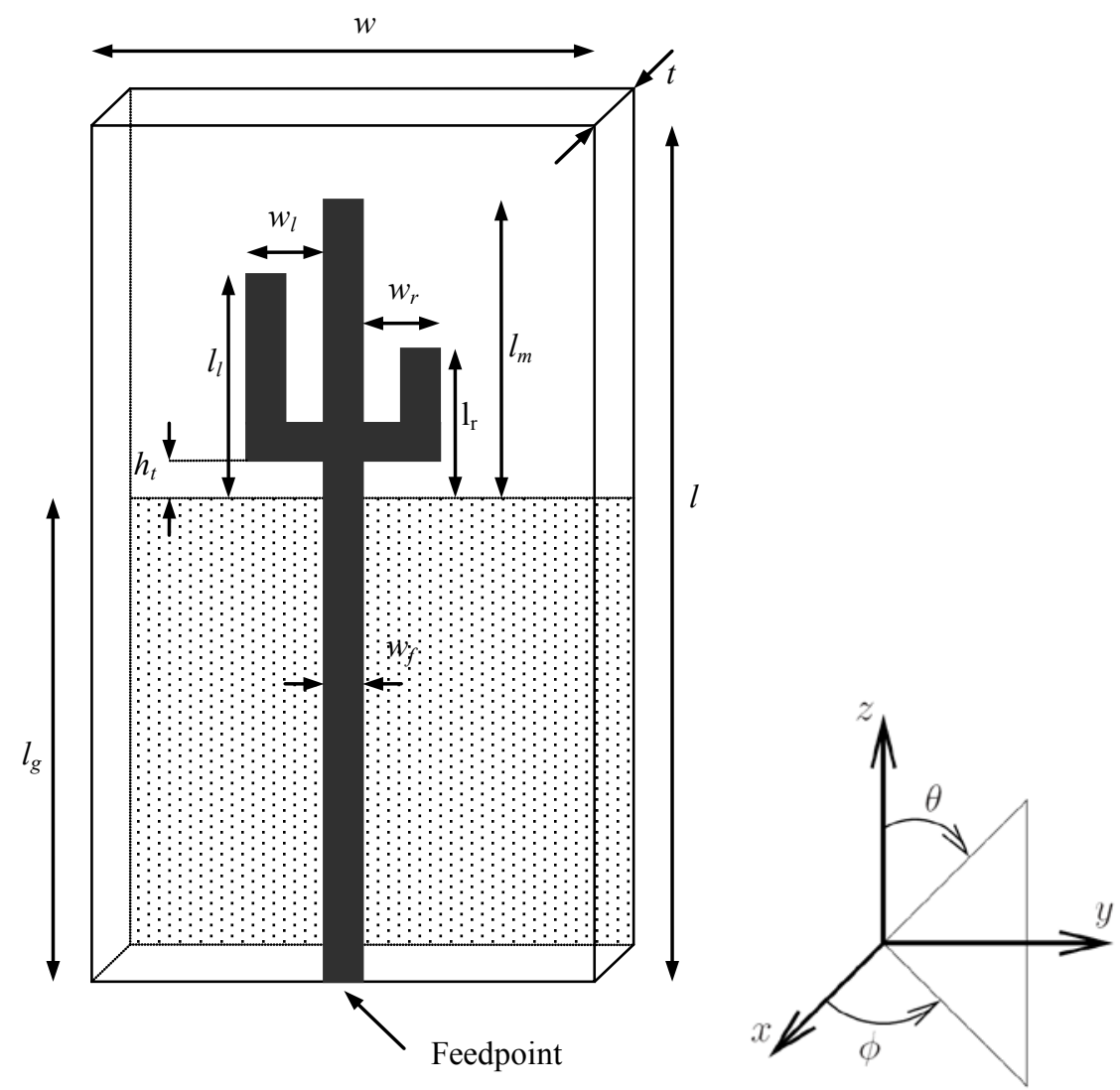

Figure 1: Geometry and coordinate system of the printed multibranch monopole

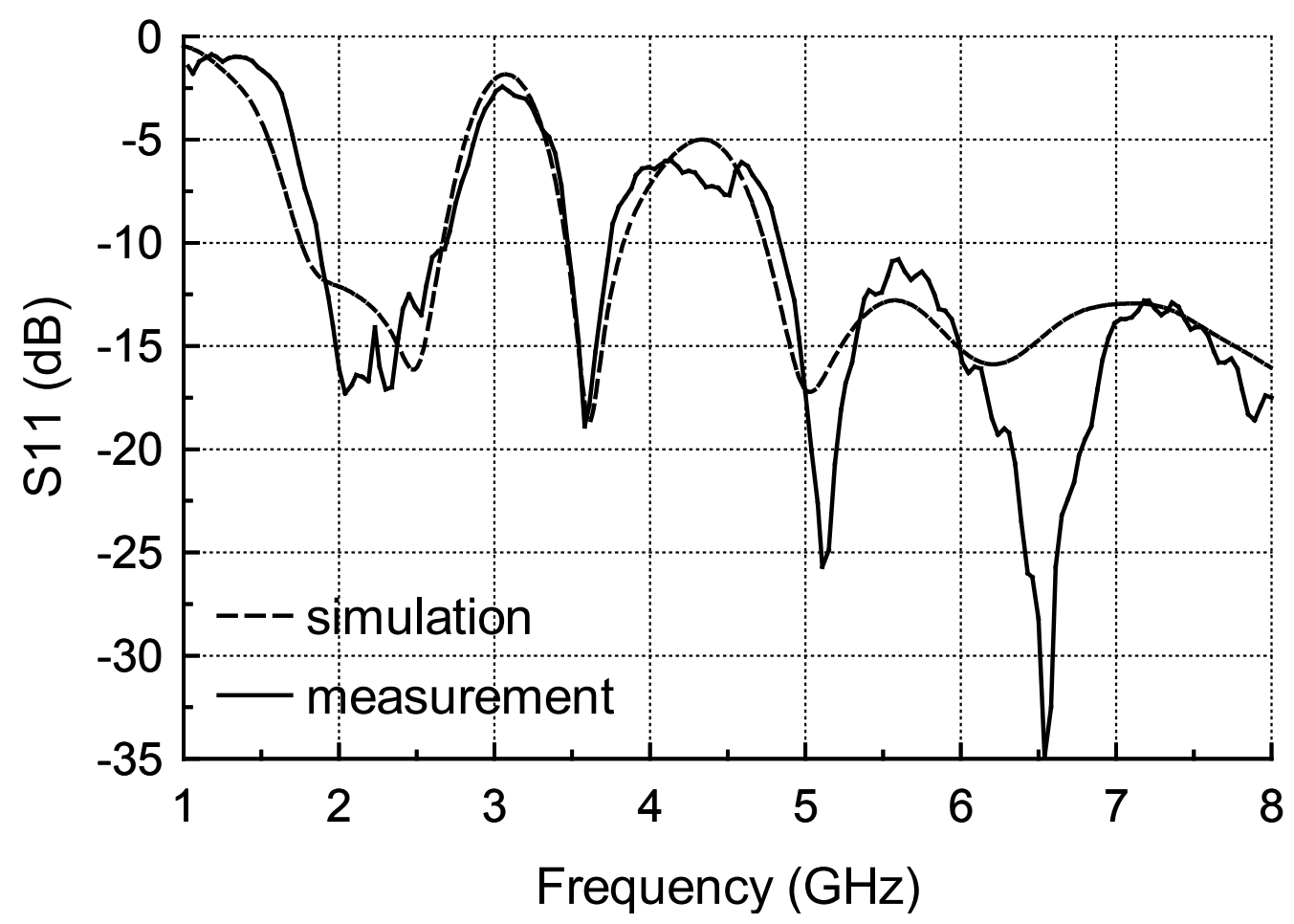

Figure 2: Measured and simulated return loss for optimised geometry 


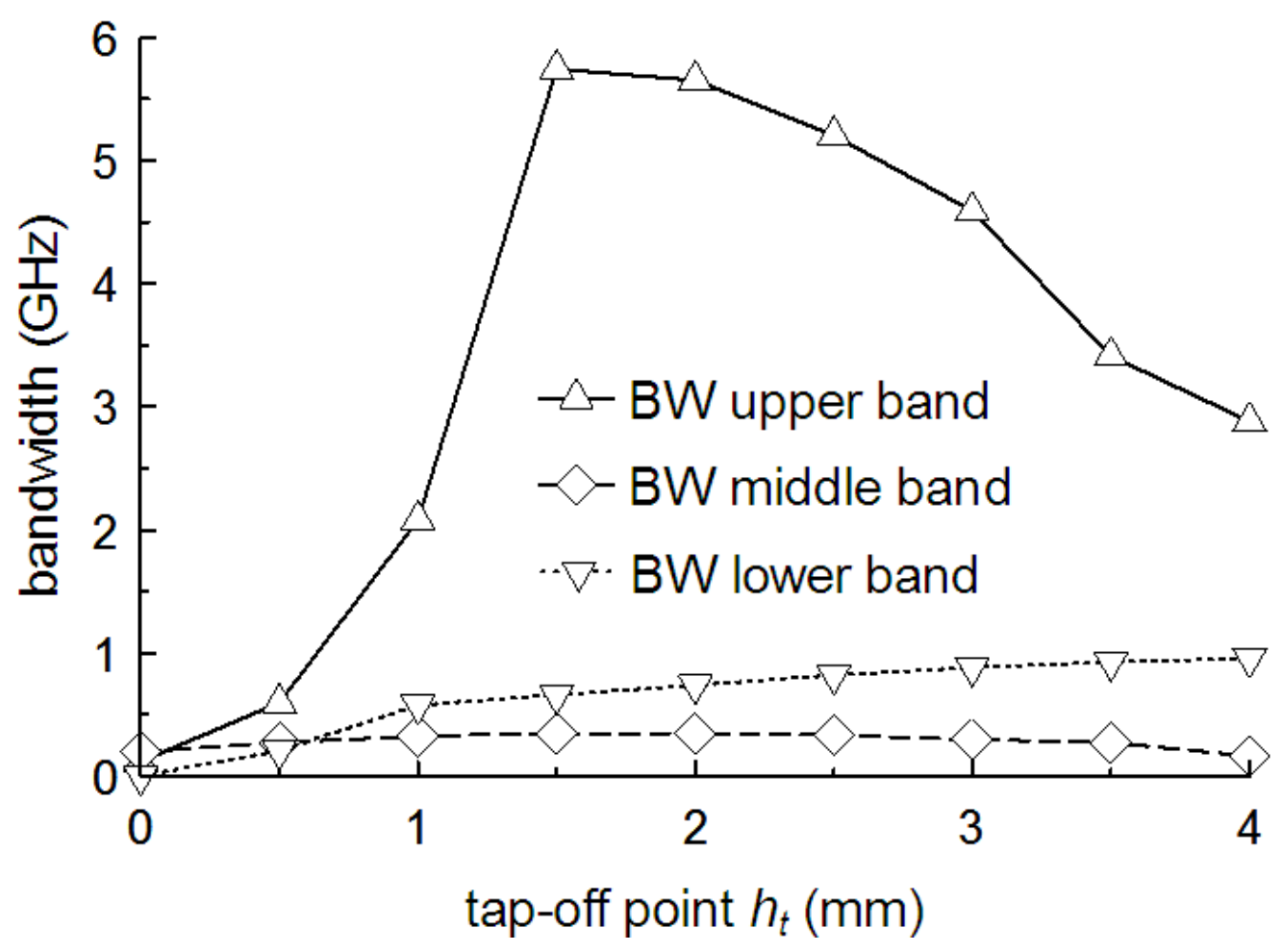

Figure 3: Impedance bandwidth dependence on tap-off point

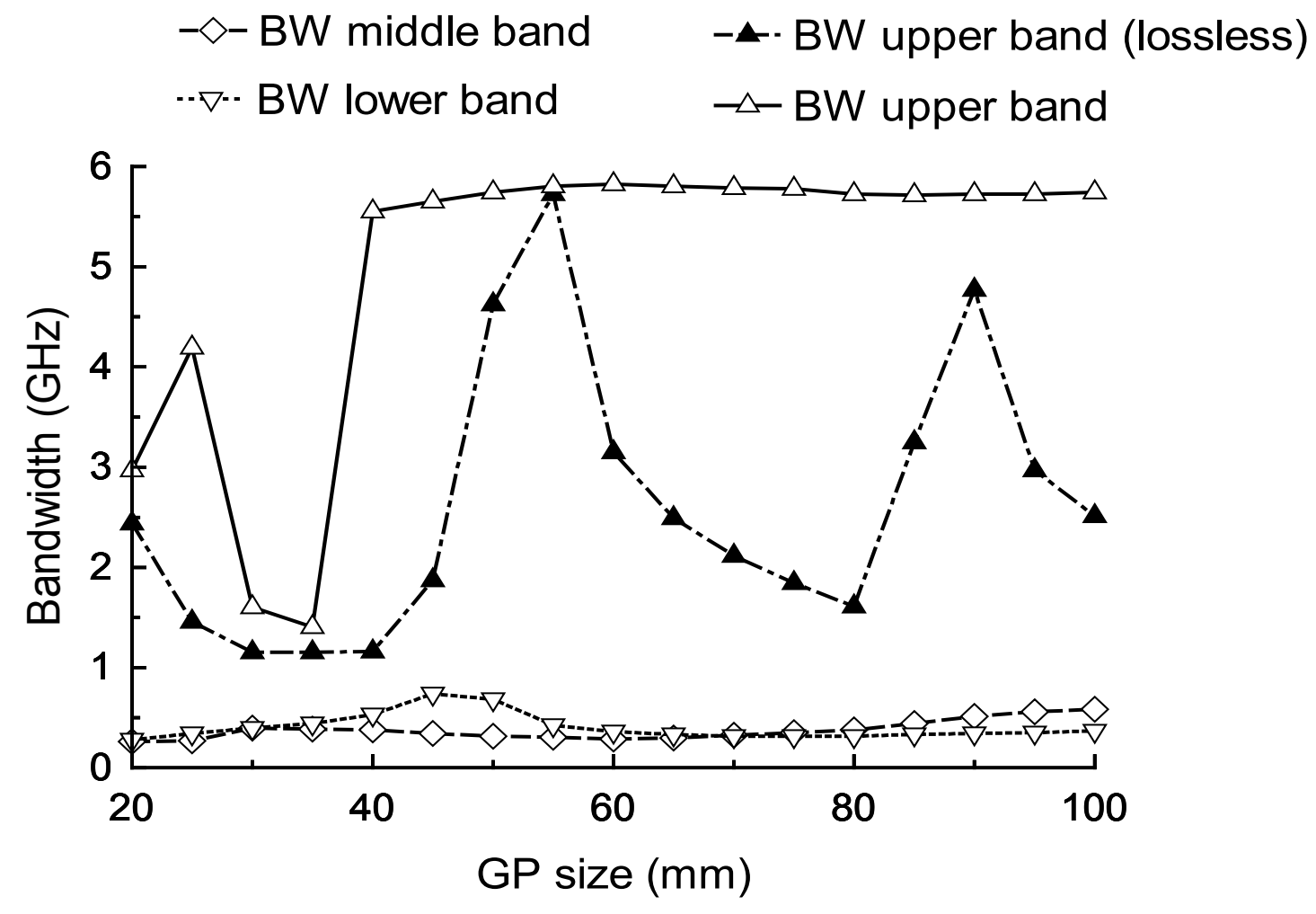

Figure 4: Impedance bandwidth dependence on groundplane size 

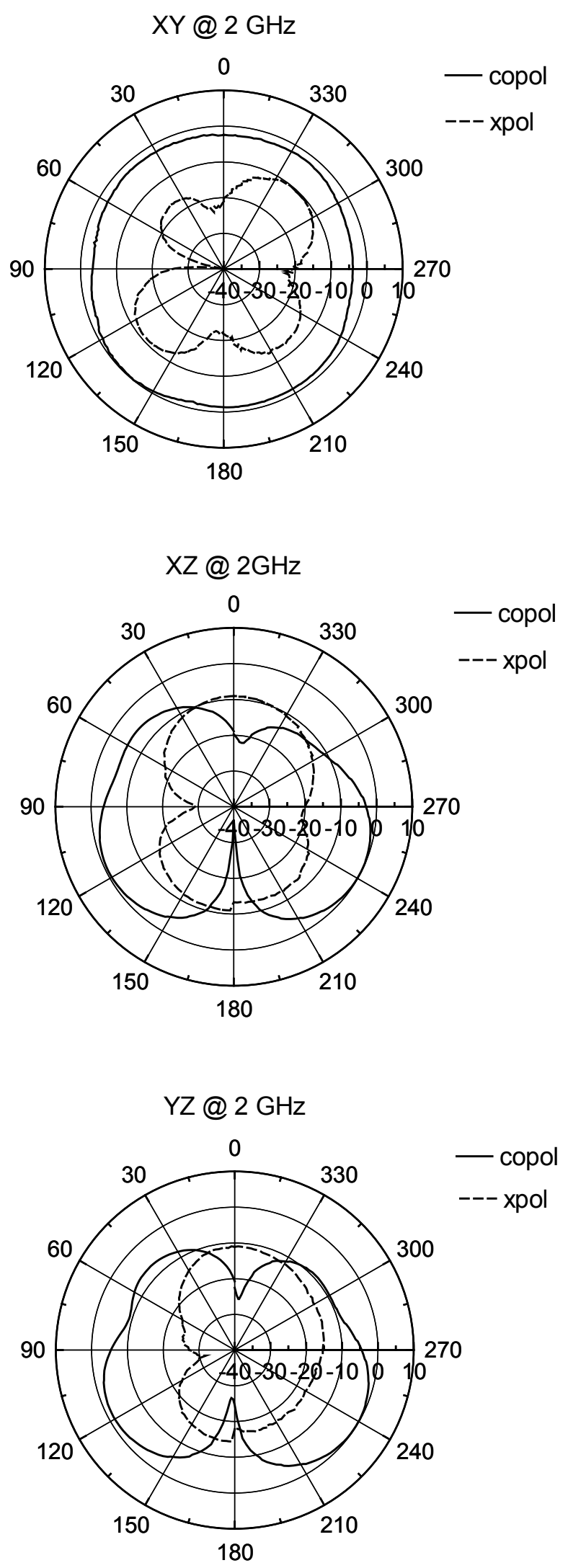

Figure 5(a) 


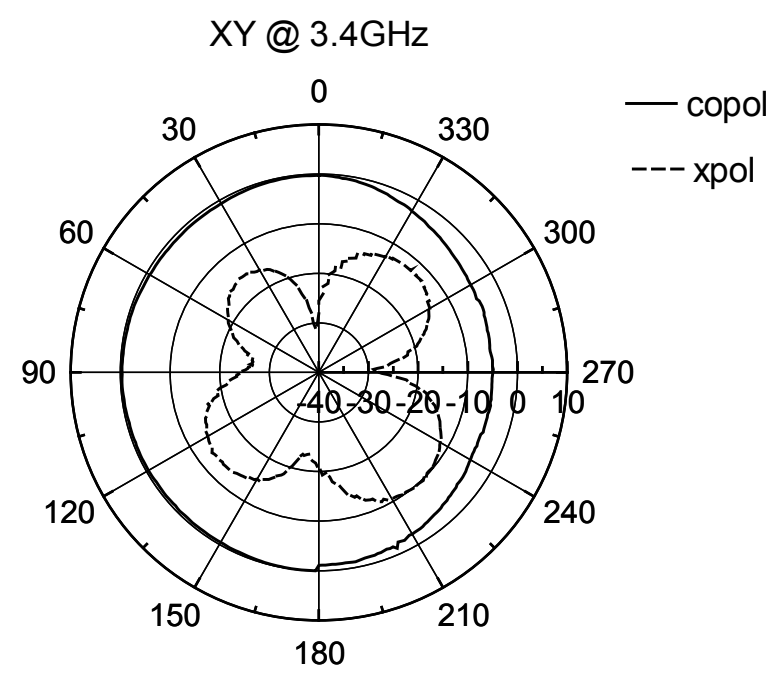

$X Z @ 3.4 G H z$

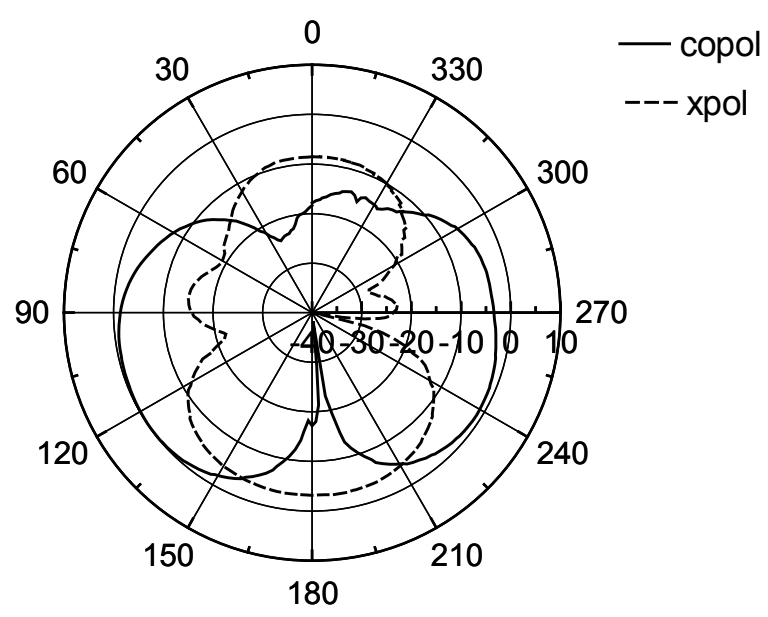

YZ @ 3.4GHz

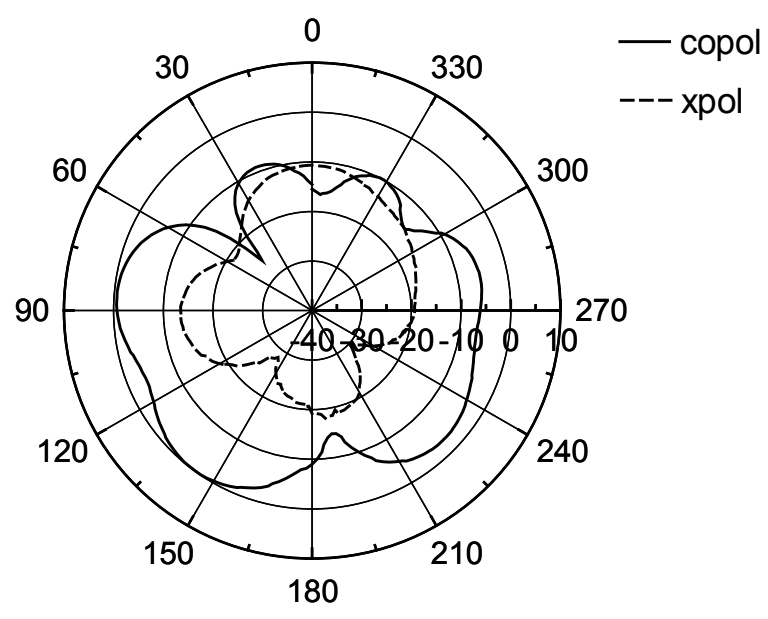

Figure 5(b) 
$X Y @ 5.5 \mathrm{GHz}$

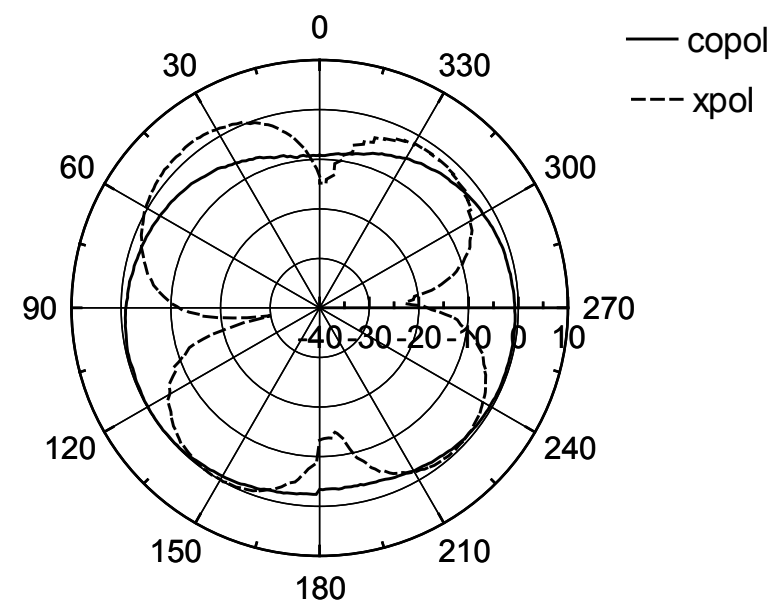

$X Z @ 5.5 \mathrm{GHz}$

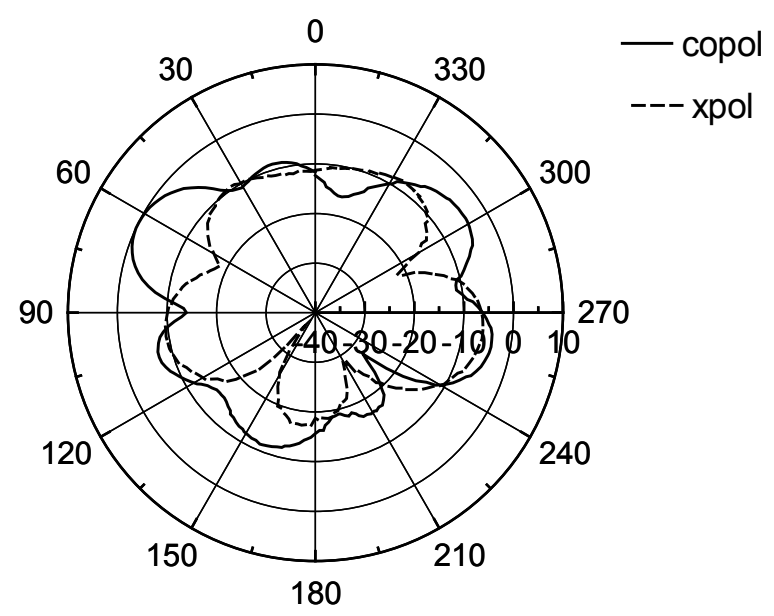

$\mathrm{YZ} @ 5.5 \mathrm{GHz}$

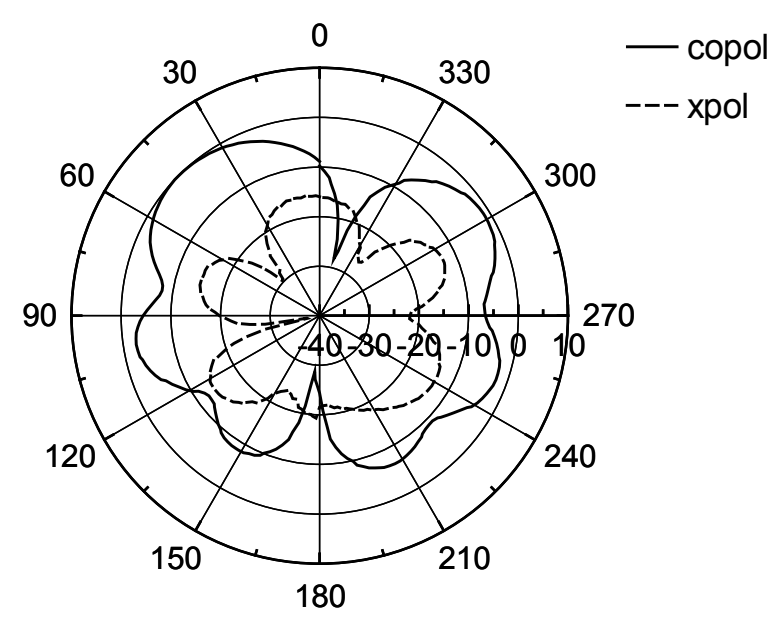

Figure 5(c)

Figure 5: Measured radiation patterns 